\title{
An ultrasound and histomorphological analysis of experimental liver cirrhosis in rats
}

\author{
J.V. Dias ${ }^{1 *}$, B.D. Paredes ${ }^{2 *}$, L.F.Q. Mesquita², A.B. Carvalho², E.O. Kozlowski, \\ A.S. Lessa1, C.M. Takiya4 ${ }^{4}$, C.M.C. Resende ${ }^{1}$, H.S.M. Coelho ${ }^{1}$, \\ A.C. Campos-de-Carvalho ${ }^{2}$, G.F.M. Rezende ${ }^{1}$ and R.C.S. Goldenberg ${ }^{2}$
}

1Departamento de Clínica Médica, Faculdade de Medicina, ${ }^{2}$ Instituto de Biofísica Carlos Chagas Filho, ${ }^{3}$ Instituto de Bioquímica Médica, ${ }^{4}$ Instituto de Ciências Biomédicas, Universidade Federal do Rio de Janeiro, Rio de Janeiro, RJ, Brasil

Correspondence to: R.C.S. Goldenberg, Instituto de Biofísica Carlos Chagas Filho, Centro de Ciências da Saúde, Av. Carlos Chagas Filho, 373, Bloco G, Sala G2-053, 21941-902 Rio de Janeiro, RJ, Brasil Fax: +55-21-2280-8193. E-mail: rcoeli@biof.ufrj.br

We investigated whether liver injury by dual exposure to ethanol and carbon tetrachloride $\left(\mathrm{EtOH}+\mathrm{CCl}_{4}\right)$ for 15 weeks would persist after hepatotoxic agents were removed $\left(\mathrm{EtOH}+\mathrm{CCl}_{4} / 8 \mathrm{wR}\right)$. After 15 weeks of hepatic injury with ethanol $(5.5 \%, \mathrm{~m} / \mathrm{v})$ and carbon tetrachloride $(0.05, \mathrm{~mL} / \mathrm{kg}$, ip), 5 of 11 female Wistar rats were sacrificed. The other 6 rats were maintained for an additional 8 weeks without hepatotoxic agents. Ultrasonography showed increased liver echogenicity and dilation of portal vein caliber in both groups $\left(\mathrm{EtOH}+\mathrm{CCl}_{4}: 0.22 \pm 0.01 \mathrm{~cm}, \mathrm{P}<0.001 ; \mathrm{EtOH}+\mathrm{CCl}_{4} / 8 \mathrm{wR}: 0.21 \pm 0.02 \mathrm{~cm}, \mathrm{P}<0.01\right)$ vs control $(0.16 \pm$ $0.02 \mathrm{~cm}$ ). Histopathology showed regenerative nodules in both experimental groups. Histomorphometry revealed increased fibrosis content in both groups $\left(\mathrm{EtOH}+\mathrm{CCl}_{4}: 12.6 \pm 2.64 \%, \mathrm{P}<0.001 ; \mathrm{EtOH}+\mathrm{CCl}_{4} / 8 \mathrm{wR}: 10.4 \pm 1.36 \%, \mathrm{P}<0.05\right)$ vs control $(2.2$ $\pm 1.21 \%$ ). Collagen types I and III were increased in groups $\mathrm{EtOH}+\mathrm{CCl}_{4}$ (collagen I: $2.5 \pm 1.3 \%, \mathrm{P}<0.01$; collagen III: $1.3 \pm 0.2 \%$, $\mathrm{P}<0.05$ ) and $\mathrm{EtOH}+\mathrm{CCl}_{4} / 8 \mathrm{wR}$ (collagen I: $1.8 \pm 0.06 \%, \mathrm{P}<0.05$; collagen III: $1.5 \pm 0.8 \%, \mathrm{P}<0.01$ ) vs control (collagen I: 0.38 $\pm 0.11 \%$; collagen III: $0.25 \pm 0.06 \%)$. Tissue transglutaminase increased in both groups $\left(\mathrm{EtOH}^{2} \mathrm{CCl}_{4}: 66.4 \pm 8 \%, \mathrm{P}<0.01 ; \mathrm{EtOH}\right.$ $\left.+\mathrm{CCl}_{4} / 8 \mathrm{wR}: 58.8 \pm 21 \%, \mathrm{P}<0.01\right)$ vs control $(7.9 \pm 0.8 \%)$. Cirrhosis caused by the association of $\mathrm{CCl}_{4}$-EtOH remained for at least 8 weeks after removal of these hepatotoxic agents. Ultrasound images can be a useful tool to evaluate advanced hepatic alterations.

Key words: Rat; Cirrhosis; Collagen; Ultrasound; $\mathrm{CCl}_{4}$; Ethanol

Research supported by FAPERJ (\#E-26/170.315/2006), CNPq (\#460408/2006-5), and CAPES-MEC (\#31001017-108D4).

${ }^{*}$ These authors contributed equally to this study.

Received January 22, 2008. Accepted November 3, 2008

\section{Introduction}

Hepatic fibrosis is an early finding in chronic liver injury characterized by failure of degradation and excessive synthesis of extracellular matrix components, mostly collagen types I and III. Persistence of the insult disrupts normal hepatic architecture, leading to development of regenerative nodules and vascular dysfunction, configuring the cirrhosis stage $(1,2)$. Hepatic cirrhosis was described as an irreversible disease, which results from the incapacity of the wounded liver to remodel fibrosis $(3,4)$. However, experimental studies with animals $(5,6)$ and humans (7-9) have recently refuted this concept. Whether advanced cirrhosis undergoes remodeling to a near nor- 
mal liver architecture is controversial (10).

Animal models of hepatic cirrhosis use carbon tetrachloride $\left(\mathrm{CCl}_{4}\right)$ extensively as a hepatotoxic agent to evaluate liver injury and recovery (10-15). Spontaneous remodeling of extracellular matrix has been reported after cessation of $\mathrm{CCl}_{4}$ intoxication leading to macronodular cirrhosis (14-16). This spontaneous recovery might limit application of these experimental models in chronic fibrosis studies and make long-term investigations of liver cirrhosis difficult when the hepatotoxic agent is interrupted.

The association of $\mathrm{CCl}_{4}$ with ethanol potentiates toxicity of the former, since it increases activation of cytochrome $\mathrm{P} 450$, the enzymatic complex responsible for $\mathrm{CCl}_{4}$ metabolism (17). This reaction leads to production of oxidative radicals that cause lipid peroxidation and, consequently, hepatotoxic injury (7). Ethanol also induces synthesis of type I collagen fibrils $(18,19)$, inhibition of hepatocyte proliferation (20-22), exacerbation of activity in hepatic stellate cells $(20,23)$, and increased expression of tissue transglutaminase (tTG) (24). Since a mechanism that renders matrix resistant to degradation results from the formation of $\varepsilon$-( $\gamma$-glutamyl) lysine cross-links by tissue transglutaminase $(5,25,26)$, use of the hepatotoxic agents in combination could be more effective in maintaining the fibrotic pattern.

The purpose of the present research was to determine if liver injury by exposure to both ethanol and $\mathrm{CCl}_{4}$ for 15 weeks would persist after the hepatotoxic agents were interrupted. Using a non-invasive diagnostic method, the ultrasound, and comparing it with the "gold standard" histological analysis for diagnosis of hepatic cirrhosis, we show that ultrasonographic images can be used to follow-up the morphological changes associated with liver injury in an experimental model of cirrhosis in rats. Furthermore, our results demonstrate that the association of ethanol and $\mathrm{CCl}_{4}$ resulted in cirrhosis, which was sustained for at least 8 weeks after insult withdrawal.

\section{Material and Methods}

\section{Animals}

This investigation conforms to "The Guide for Care and Use of Laboratory Animals" [DHHS Publication No. (NIH) 85-23, revised 1996, Office of Science and Health Reports, Bethesda, MD] and was approved by the Ethics Committee of Instituto de Biofísica Carlos Chagas Filho (protocol \#021).

Female Wistar rats were obtained from the Instituto de Biofísica Carlos Chagas Filho (IBCCF, Rio de Janeiro, RJ, Brazil). Animals were housed at controlled temperature $\left(23^{\circ} \mathrm{C}\right)$ with daily exposure to a $12: 12$-light-dark cycle.

\section{Chronic liver injury model}

Cirrhosis was induced in 11 female Wistar rats ( 3 to 4 months of age, weighing 150-200 g) with injections of a $20 \%$ solution of $\mathrm{CCl}_{4}$ (1:5 in olive oil, dose of $0.05 \mathrm{~mL} / \mathrm{kg}$ ) intraperitoneally (ip) three times a week on alternate days for 15 weeks. In response to the need to develop an animal model with an alcohol consumption of clinical relevance, while maintaining dietary control, an alcohol liquid diet in accordance with the AIN-93 guidelines (27) was administered for 15 weeks. Prior to $\mathrm{CCl}_{4}$ administration, an adaptation phase was carried out with a non-alcoholic liquid diet (control diet) administered for 1 week followed by a second week of the ethanol diet $\left(\mathrm{EtOH}+\mathrm{CCl}_{4}\right)$. Control diet ingredients were identical to those used in the alcoholic diet, except that ethanol was replaced by water in the same volume. Rats were given ad libitum access to liquid diets.

After 15 weeks, 5 animals were sacrificed and the remaining 6 animals were returned to the standard chow and water diet. They were sacrificed 8 weeks after removal $(8 w R)$ of the hepatotoxic agents $\left(\mathrm{EtOH}+\mathrm{CCl}_{4} / 8 w R\right)$.

A control group consisting of 7 age- and sex-matched animals was fed the liquid diet without alcohol. Three of these animals were sacrificed at the end of the 15th week (Ctrl) and the remaining 4 animals were sacrificed 8 weeks after discontinuation of hepatotoxic agents (Ctrl/8wR).

\section{Ultrasound examination}

Animals were anesthetized and placed in the supine position breathing spontaneously. Trichotomy was performed and a $10-\mathrm{MHz}$ linear transducer of a Caris Plus ${ }^{\circledR}$ ultrasound equipment (Esaote, Italy) was used to analyze the portal vein caliber and liver parenchyma echogenicity.

\section{Histology}

Animals were sacrificed after either 15 weeks of chronic liver injury or 8 weeks after toxic induction interruption. Liver tissue slices were fixed for $5 \mathrm{~h}$ in Bouin's solution followed by overnight exposure to $10 \%$ buffered formalin solution, $\mathrm{pH} 7.2$, and then embedded in paraffin. Liver samples were sectioned $(5 \mu \mathrm{m})$ and stained with hematoxylin and eosin (H\&E) and picrosirius according to standard protocols (28).

\section{Collagen quantification}

Quantification of fibrillar collagen content was performed by histomorphometric analysis. Using a digital Qcolor 5 camera (Olympus, Japan) coupled to an epifluorescence microscope (Axiovert 100, Zeiss, Germany), ten randomly picked fields (10X magnification) of picrosiriusstained liver slides (5- $\mu$ m sections) were scored for each animal at a final magnification of 100X. Images were 
analyzed using the Image Pro Plus 5.0 software (Media Cybernetics, USA). Using the "measurement" tool window, images were prepared for analysis using "erode" filter tool for best determination of each pixel to analyze. Red areas were selected using the following settings: "count/size" option was set to manual and "sensitivity" was set to 5 . The same settings were used to select the total field area. Collagen quantification was reported as \% of red-stained area divided by the total area times 100 .

The determination of liver collagen content was performed by measuring hydroxyproline (29). In short, $2 \mathrm{~g}$ fresh hepatic tissue from each animal was dehydrated in acetone for 2 days and dried for $24 \mathrm{~h}$ at $60^{\circ} \mathrm{C}$. Dry tissue samples were mashed, homogenized and stored at $4^{\circ} \mathrm{C}$. Ten milligrams of the dry samples was hydrolyzed in $6 \mathrm{M}$ $\mathrm{HCl}$ for $18 \mathrm{~h}$ at $107^{\circ} \mathrm{C}$. Samples were suspended in $200 \mu \mathrm{L}$ buffered solution ( $5 \%$ citric acid, $1.2 \%$ acetic acid, $12 \%$ sodium acetate, and $3.4 \%$ sodium hydroxide, $\mathrm{pH} 6.0,1: 10$ dilution in distilled water) and incubated with $1 \mathrm{~mL}$ chloramine-T (60 mM in 50\% n-propanol, $\mathrm{pH} \mathrm{6.0)} \mathrm{for} 20 \mathrm{~min}$ at $38^{\circ} \mathrm{C}$. Finally, samples were incubated with $1 \mathrm{~mL}$ aldehyde/perchloric acid solution (1 M 4-(dimethylamino)-benzaldehyde in $16 \%$ perchloric acid and $60 \%$ n-propanol) for $20 \mathrm{~min}$ at $60^{\circ} \mathrm{C}$. Absorbance was read at $570 \mathrm{~nm}$. Concentration was determined by the linear regression equation of a standard calibration curve (range: 0-20 $\mu \mathrm{g}$ ) of 4-hydroxyproline (Sigma-Aldrich, USA).

\section{Immunofluorescence}

Liver tissue was embedded in Tissue-Tek ${ }^{\mathrm{TM}}$ OCT compound (Sakura, Japan) and preserved at $-70^{\circ} \mathrm{C}$. Six-micrometer sections of the liver samples were obtained with a cryostat at $-20^{\circ} \mathrm{C}$ and fixed in acetone. Indirect immunofluorescence technique was performed using anti-tTG (Stratech Scientific, England) at 1:40 and anti-collagen types I and III antibodies (Chemicon International, USA) at 1:30. Secondary antibodies were FITC goat anti-mouse IgG $(\mathrm{H}+\mathrm{L})$ (at 1:50; Zymed Laboratories, USA) for tTG and FITC goat anti-rabbit IgG $(\mathrm{H}+\mathrm{L})$ (at 1:50; Zymed) for collagen types I and III (28). As control, liver sections were incubated with non-immune mouse or rabbit serum instead of antibodies, followed by incubation with secondary antibodies. Quantification of TTG and collagen types I and III by immunofluorescence was performed as described above in histomorphometric analysis.

\section{Statistical analysis}

Statistical differences among means were assessed using ANOVA with the Tukey post-test for multiple comparisons. $P<0.05$ was considered to be statistically significant. Data are reported as mean $\pm S D$.

\section{Results}

\section{Control groups}

There were no statistical differences between the control group sacrificed at 15 weeks ( $\mathrm{Ctrl}, \mathrm{N}=3$ ) and the control group sacrificed at 23 weeks $(\mathrm{Ctrl} / 8 w R, N=4)$ for any of the parameters analyzed (data not shown). Thus, data for both control groups were combined into one group named control group $(\mathrm{N}=7)$.

\section{Ultrasound assessment}

Ultrasound analysis showed increased liver echogenicity characterized by an extensive coarsened and heterogeneous parenchyma with disorganized hepatic surface after 15 weeks of injury induction. This same pattern was still observed 8 weeks after intoxication was interrupted, which is consistent with the diagnosis of cirrhosis (compare control to other groups in Figure 1A, E, and I). There was an increase in portal vein caliber in both groups $(\mathrm{EtOH}$ $+\mathrm{CCl}_{4}: 0.22 \pm 0.01 \mathrm{~cm}, \mathrm{P}<0.001 ; \mathrm{EtOH}+\mathrm{CCl}_{4} / 8 \mathrm{wR}: 0.21$ $\pm 0.02 \mathrm{~cm}, \mathrm{P}<0.01)$ compared with the control group $(0.16$ $\pm 0.02 \mathrm{~cm}$ )

\section{Histology}

Macroscopically, the liver of the control group had a brownish-red color, a smooth surface and elastic consistency (Figure 1B). Microscopically, hepatocytes were radially arranged in plates aligned to sinusoids converging to centrolobular veins (Figure 1C). Moreover, picrosirius only stained portal spaces and centrolobular vessels (Figure 1D).

At the 15th week of induction, there was clear evidence of macronodular cirrhosis. The liver surface was extremely irregular with multiple nodules and had a rigid consistency (Figure 1F). Histological analysis showed liver cirrhosis, characterized by global loss of normal parenchymal architecture, and formation of nodules separated by collagen septa containing some inflammatory infiltrate (Figure 1G). Collagen deposition was intense, forming thick septa interconnecting regenerative nodules (Figure $1 \mathrm{H}$ ).

After 8 weeks of recovery, the $\mathrm{EtOH}+\mathrm{CCl}_{4} / 8 \mathrm{wR}$ group presented the same macroscopic and microscopic patterns found in the $\mathrm{EtOH}+\mathrm{CCl}_{4}$ group (Figure $1 \mathrm{~J}, \mathrm{~K}$, and $\mathrm{L}$ ) indicating that cirrhosis was sustained after aggression was interrupted.

\section{Collagen quantification}

Morphometric analysis of picrosirius-stained areas showed an increase in fibrillar collagen content in both groups $\left(\mathrm{EtOH}+\mathrm{CCl}_{4}: 12.6 \pm 2.64 \%, \mathrm{P}<0.001\right.$; $\mathrm{EtOH}+$ $\left.\mathrm{CCl}_{4} / 8 \mathrm{wR}: 10.4 \pm 1.36 \%, \mathrm{P}<0.05\right)$ compared with the 

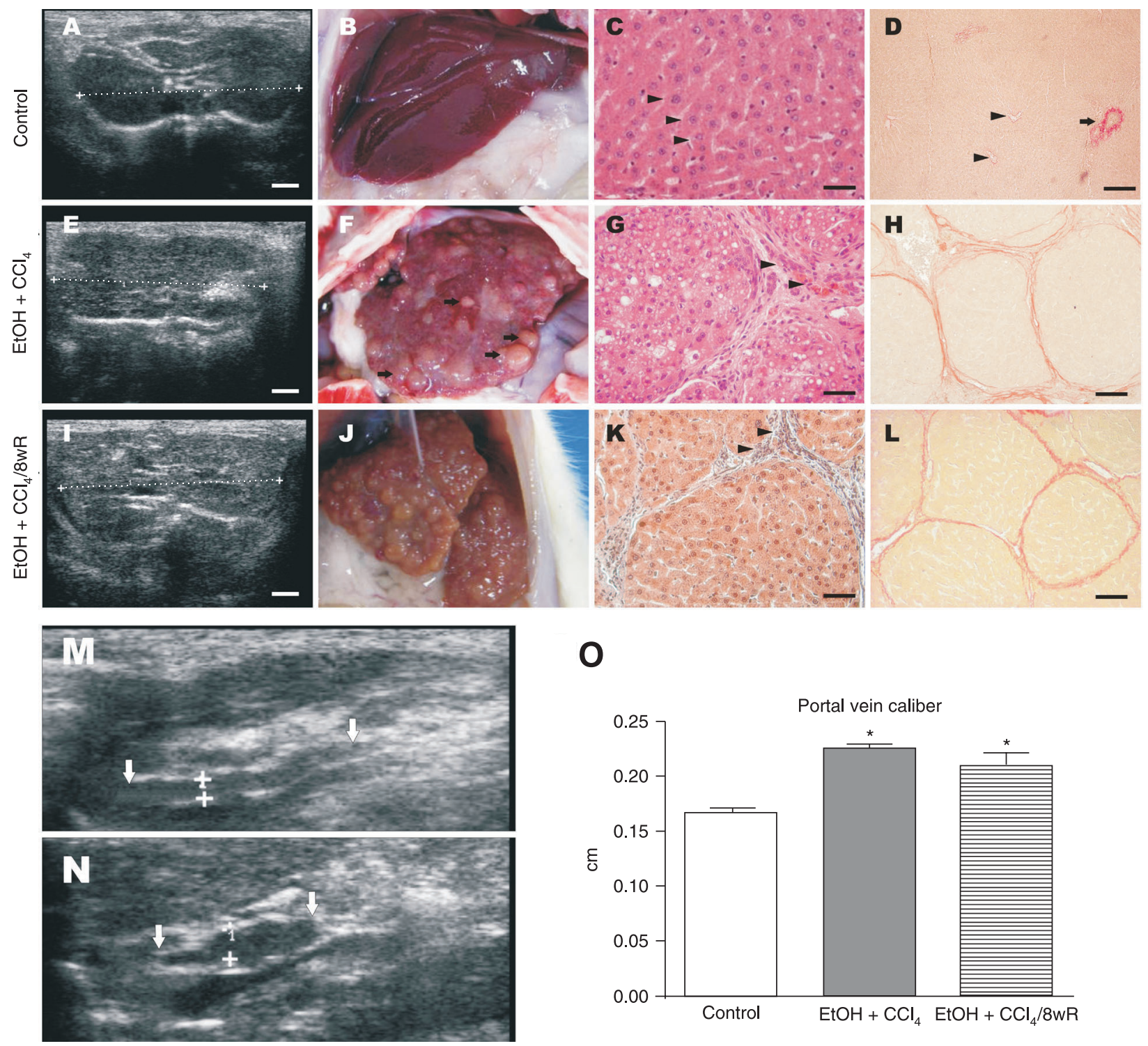

Figure 1. Ultrasonographic images, histology and measurement of portal vein caliber. Normal liver $(\mathrm{N}=5)$ : $A$, ultrasonographic image illustrates homogeneous liver echotexture with regular contours. $B$, Macroscopy of normal liver. Note smooth surface and brownishred color. $C$, Microscopy of normal liver (H\&E). The parenchyma is homogeneous showing hepatocytes (arrowheads) with round nuclei and sinusoids with radial arrangement. $D$, Picrosirius staining indicates collagen in red. Deposition occurs only in vessels (portal triad - arrow; central vein - arrowheads). After 15 weeks of induction $(\mathrm{N}=5)$ : $E$, ultrasonographic image illustrates coarse liver echotexture; $F$, liver cirrhosis: irregular surface and multiple nodules (arrows). G, Microscopy shows modification of liver normal structure, with inflammatory infiltrate (arrowheads) and tissue necrosis (H\&E). H, Picrosirius staining indicates deposition of collagen in thick septa, forming regeneration nodules. Eight weeks after chronic injury interruption $(N=6)$ : $I$, ultrasonographic image illustrates the same pattern as observed after 15 weeks of induction with a diffuse coarse liver echotexture. $J$, Macroscopy shows nodules on liver surface. $K$, Microscopy shows thick fibrous septa (arrowheads), and $L$, regenerative nodules as seen at 15 weeks. Portal vein caliber (PVC): $M$, ultrasonographic image shows normal PVC in control group (arrows); $N$, ultrasonographic image shows dilated and tortuous portal vein representative of both intoxicated groups (arrows), and $O$, quantification of PVC shows increase in portal vein caliber $(0.24 \mathrm{~cm})$ in both groups intoxicated with ethanol and $\mathrm{CCl}_{4}$ compared with control group $(0.14 \mathrm{~cm})$. Data are reported as means $\pm \mathrm{SD}$. ${ }^{*} \mathrm{P}<0.01$ compared to control group (ANOVA with the Tukey post-test for multiple comparisons). Calibration bars for ultrasonographic liver images: $5 \mathrm{~mm}$; for H\&E: $50 \mu \mathrm{m}$; for picrosirius: $100 \mu \mathrm{m}$, except for Figure $1 \mathrm{D}(40 \mu \mathrm{m})$. 
control group (2.2 $\pm 1.21 \%$; Figure $2 \mathrm{~A})$.

Hydroxyproline (HYP) is an amino acid found almost exclusively in collagen proteins. Sample concentration of HYP has a direct correlation with the amount of fibrosis in the liver. There was an increase in HYP concentration $(\mu \mathrm{g} /$ $\mathrm{g}$ tissue) in both groups $\left(\mathrm{EtOH}+\mathrm{CCl}_{4}: 1.9 \pm 0.035, \mathrm{P}<\right.$ $\left.0.001 ; \mathrm{EtOH}+\mathrm{CCl}_{4} / 8 \mathrm{wR}: 1.6 \pm 0.18, \mathrm{P}<0.05\right)$ compared with the control group $(1.2 \pm 0.17)$ (Figure 2B).

\section{Immunofluorescence}

We performed immunofluorescence assays to evaluate the presence of tTG in cirrhotic liver. In Figure 3A, there is deposition of tTG only in perivascular regions in a normal liver. The $\mathrm{EtOH}+\mathrm{CCl}_{4}$ group, as shown in Figure 3B,
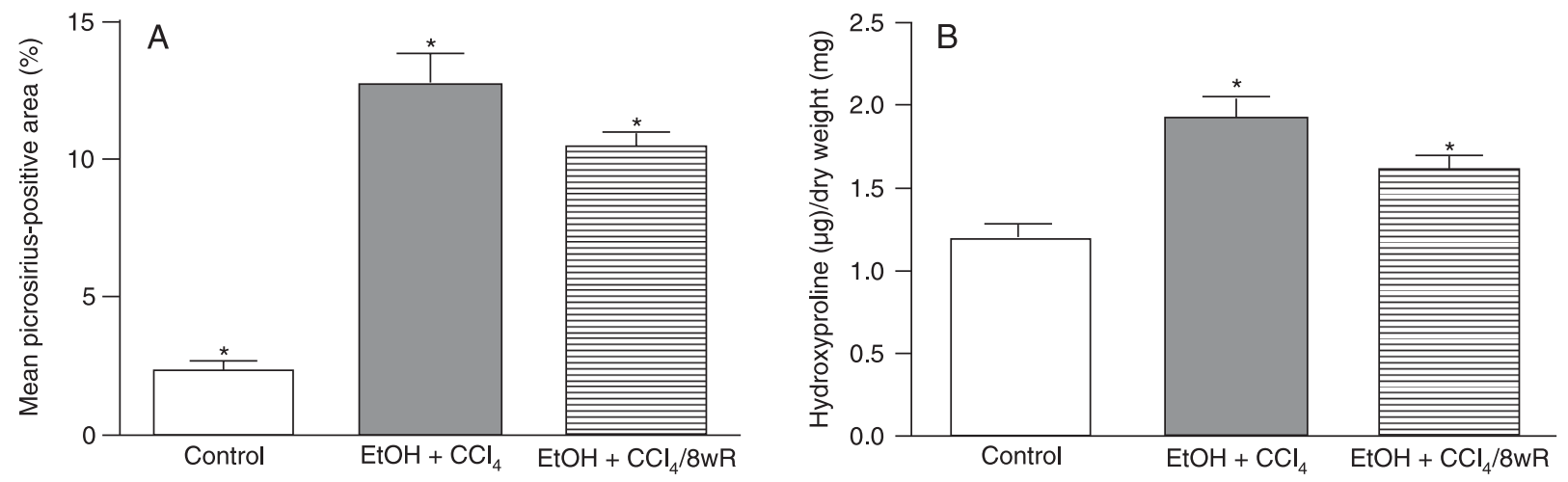

Figure 2. Picrosirius morphometric analysis (A) shows that chronic cirrhosis induction for 15 weeks leads to an increase in the amount of fibrosis compared with the control group $(\mathrm{N}=5)$. The fibrillar collagen content was sustained 8 weeks after interruption of induction $(N=6)$. Hydroxyproline assay (B) showed an increase in liver collagen content after 15 weeks of cirrhosis induction and 8 weeks after interruption. Data are reported as means $\pm S D$. ${ }^{*} P<0.01$ compared to control group $(N=7$; ANOVA with the Tukey post-test for multiple comparisons).
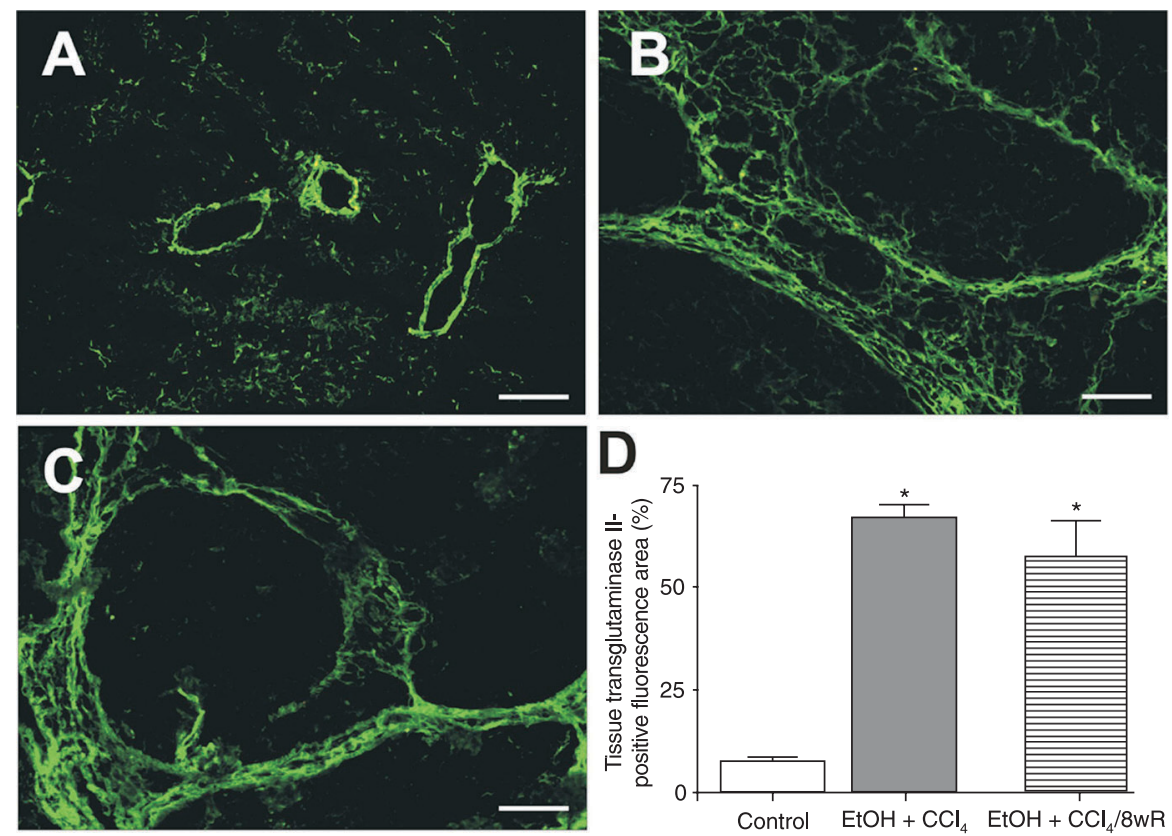

Figure 3. Immunofluorescence for tissue transglutaminase (tTG). $A$, In the control group tTG is present only around vessels ( $N=3$ ). $B$, Septal stain indicates an increase of this enzyme for 15 weeks $\left(\mathrm{EtOH}+\mathrm{CCl}_{4} ; \mathrm{N}=4\right)$. $C$, Hepatic nodules are still stained 8 weeks after interruption of ethanol and $\mathrm{CCl}_{4}$, indicating that $\mathrm{tTG}$ is still present after this period $(\mathrm{N}=5$.) $D$, Morphometric analysis shows an increase in TTG enzyme in all groups compared with the control group. Data are reported as means $\pm S D$. ${ }^{*} P<0.01$ compared to control group (ANOVA with the Tukey post-test for multiple comparisons). Calibration bar: $100 \mu \mathrm{m}$ for panels A-C. 
presented intense deposition of this enzyme. This same pattern was also observed in the $\mathrm{EtOH}+\mathrm{CCl}_{4} / 8 \mathrm{wR}$ group (Figure 3C).

Quantification of the area stained with tTG showed that there was an increase in the deposition of this enzyme in both groups $\left(\mathrm{EtOH}+\mathrm{CCl}_{4}: 66.4 \pm 8 \%, \mathrm{P}<0.01\right.$; $\mathrm{EtOH}+$ $\left.\mathrm{CCl}_{4} / 8 \mathrm{wR}: 58.8 \pm 21 \%, \mathrm{P}<0.01\right)$ compared with the control group $(7.9 \pm 0.8 \%$; Figure $3 \mathrm{D})$.

In order to determine collagen isotypes, collagen types I and III were detected by immunofluorescence. In normal rats, both collagens were detected in portal spaces and as tiny fibrils in liver parenchyma (Figure $4 A$ and B). After 15 weeks of induction, both types of collagen were deposited in hepatic septa (Figure 4C and D). A similar pattern was still observed at the 8th week after aggression was interrupted (Figure 4E and F).

Collagen quantification showed an increase in both collagen I and II in groups $\mathrm{EtOH}+\mathrm{CCl}_{4}$ (collagen I: $2.5 \pm$
1.3\%, P < 0.01; collagen III: $1.3 \pm 0.2 \%, \mathrm{P}<0.05)$ and $\mathrm{EtOH}$ $+\mathrm{CCl}_{4} / 8 \mathrm{wR}$ (collagen I: $1.8 \pm 0.06 \%, \mathrm{P}<0.05$; collagen III: $1.5 \pm 0.8 \%, P<0.01)$ compared with the control group (collagen I: $0.38 \pm 0.11 \%$; collagen III: $0.25 \pm 0.06 \%$ ) (Figure $4 \mathrm{G}$ and $\mathrm{F}$ ).

\section{Discussion}

We have established and characterized an experimental model of cirrhosis in rats by inducing liver aggression for 15 weeks with a combination of $\mathrm{CCl}_{4}$ and alcohol. In this model, cirrhosis was sustained for at least 8 weeks after insult withdrawal.

Hepatic cirrhosis is characterized by failure of degradation and excessive synthesis of the extracellular matrix (1). One major limitation of experimental cirrhosis models is the lack of tools that allow longitudinal studies of fibrotic change in the liver of individual rats (5). The "gold stand-
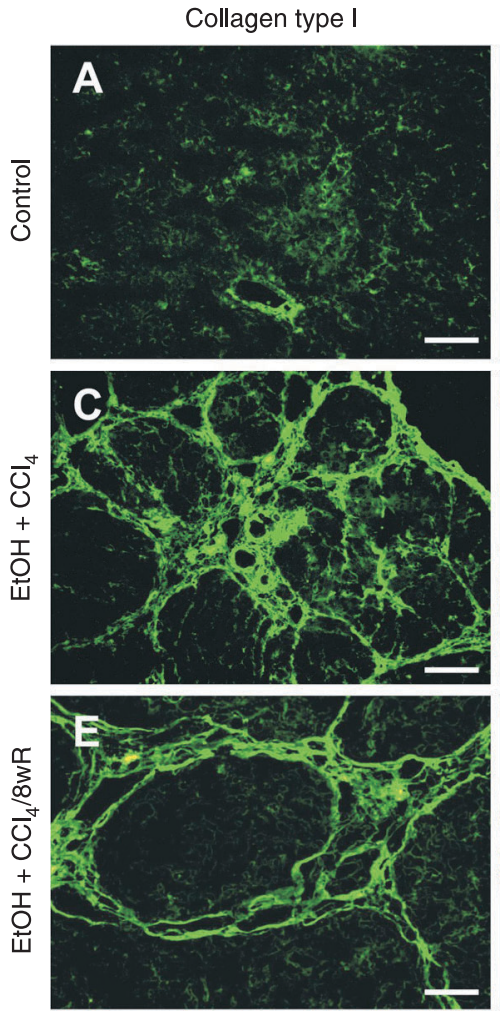
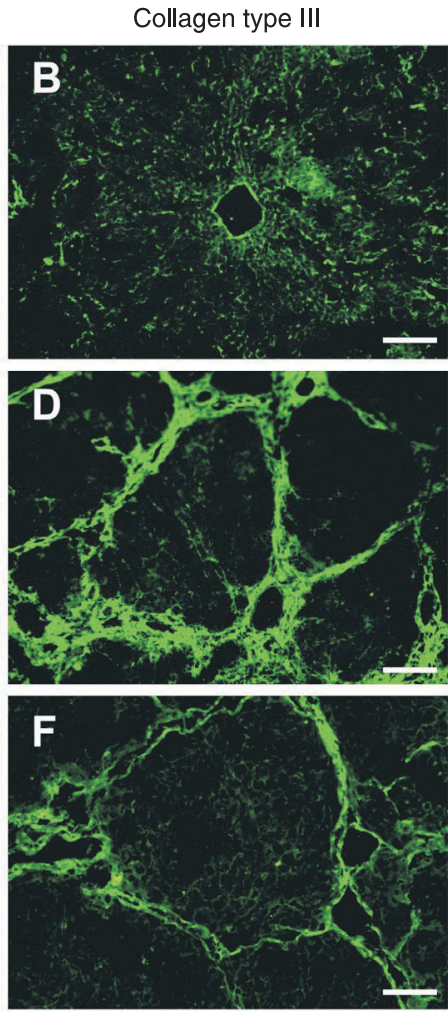

G

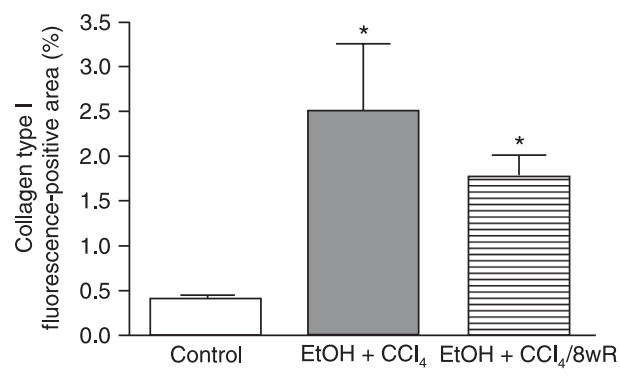

$\mathrm{H}$

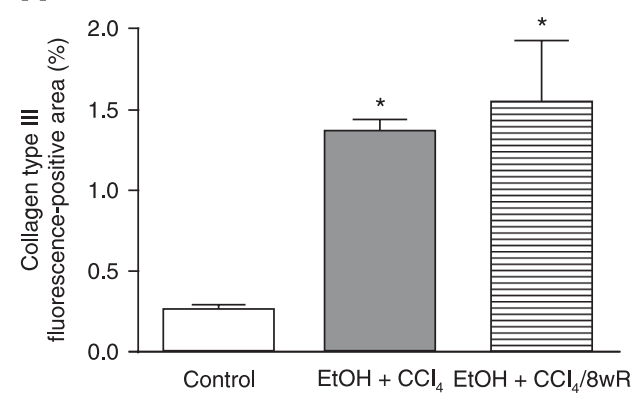

Figure 4. Immunofluorescence of collagen types I and III. Collagen type I (A) and type III (B) detection in normal hepatic parenchyma $(\mathrm{N}=3)$. After intoxication for 15 weeks $\left(\mathrm{EtOH}+\mathrm{CCl}_{4} ; \mathrm{N}=3\right)$, both collagen types $(\mathrm{C}$ and $\mathrm{D})$ have increased expression. This same pattern of staining was observed in the group with interrupted chronic liver injury $\left(\mathrm{EtOH}+\mathrm{CCl}_{4} / 8 \mathrm{wR} ; \mathrm{N}=5\right)(\mathrm{E}$ and $\mathrm{F})$. Morphometric analysis of collagen type I $(\mathrm{G})$ and type III $(\mathrm{H})$ shows an increase of both collagen types at 15 weeks of intoxication and 8 weeks after interruption of chronic liver injury. Data are reported as means $\pm S D$. ${ }^{*} P<0.01$ compared to control group (ANOVA with the Tukey post-test for multiple comparisons). Calibration bar: $100 \mu \mathrm{m}$ for panels A-F. 
ard" for diagnosis of liver cirrhosis has been histopathological examination (1), which demands invasive procedures such as biopsy or whole organ removal after animal sacrifice. The present study shows a correlation between ultrasound parameters and histological analysis. Ultrasound images demonstrated increased liver echogenicity with a coarse pattern and nodular surface indicating a severe tissue alteration over time, which was confirmed by histological results. In addition, dilation of the portal vein was also sustained after induction was interrupted. Portal vein remodeling is directly related to portal hypertension, a severe complication of liver cirrhosis (30). We suggest the use of ultrasound analysis as a useful tool to follow up chronic hepatic injury and to diagnose cirrhosis.

Studies using chronic injection of $\mathrm{CCl}_{4}$ have been performed to determine spontaneous reversal of hepatic fibrosis/cirrhosis $(5,6,14,31)$. Following chronic induction for 12 weeks, micronodular cirrhosis developed and underwent remodeling resulting in macronodular cirrhosis 28 days after withdrawal of intoxication (5). In another study, hepatic cirrhosis was established after 16 weeks of $\mathrm{CCl}_{4}$ administration, but fibrous septa presented thinning and disruption after one-month recovery, remodeling to enlarged regenerative nodules (6). The reversal seen in these models of chronic liver injury may reflect the wellknown liver regenerative capability. An important issue concerning the reversal process is the presence of mature fibrosis areas with broad collagen septa and extensively cross-linked by tTG, an enzyme that stabilizes the extracellular matrix, rendering the collagen fibers less sensitive to proteolytic degrading $(32,33)$. These areas do not undergo remodeling and can represent the limit of matrix reversal (5). In our model, the combined effect of two hepatotoxic agents (ethanol and $\mathrm{CCl}_{4}$ ) seems to surpass endogenous spontaneous regeneration, leading to a minimum reversal process over 8 weeks. Although we did not study animals for longer periods of recovery, eight weeks

\section{References}

1. Anthony PP, Ishak KG, Nayak NC, Poulsen HE, Scheuer PJ, Sobin LH. The morphology of cirrhosis. Recommendations on definition, nomenclature, and classification by a working group sponsored by the World Health Organization. J Clin Pathol 1978; 31: 395-414.

2. Bataller R, Brenner DA. Liver fibrosis. J Clin Invest 2005; 115: 209-218.

3. Benyon RC, Iredale JP. Is liver fibrosis reversible? Gut 2000; 46: 443-446.

4. Bioulac-Sage P, Blanc JF, Lepreux S, Balabaud C, is a useful time window that can be used to study drug- or cell-based therapies.

Collagen types I and III show a three- to eight-fold increase in hepatic injury (34). These proteins are mainly synthesized by activated hepatic stellate cells. Type I procollagen expression in activated hepatic stellate cells is stimulated when these cells are exposed to ethanol in culture (18,35-37). Both collagen types are substrates for tTG (38).

We have identified histological and biochemical features associated with irreversibility of fibrosis. The association of ethanol and $\mathrm{CCl}_{4}$ in the present study resulted in a large amount of tTG localized mainly at fibrous septa at the end of 15 weeks of intoxication, a period when chronic cellular injuries are at the highest level and tTG is linked to extracellular matrix. We suggest that the presence of tTG 8 weeks after chronic liver injury discontinuation can contribute to the elevated amounts of collagen types I and III observed at this time in the present study. Collagen crosslinking makes this molecule more resistant to collagenase degradation, therefore inhibiting fibrosis remodeling. In agreement with other reports $(5,20)$, our results showed that the persistent presence of tTG after withdrawal of toxic agents might determine a point of "no return" for hepatic cirrhosis.

Our observations show that ultrasound images can be used as a useful tool to evaluate advanced hepatic fibrotic change. Moreover, we suggest that the presence of tTG, after discontinuation of toxic agents, might contribute to collagen resistance to degradation, leading to irreversible hepatic fibrosis.

\section{Acknowledgments}

The authors are grateful to Mr. Kevin W. Brady for reviewing the manuscript. 
rats. Pathol Res Pract 2005; 201: 449-456.

7. Wanless IR, Nakashima E, Sherman M. Regression of human cirrhosis. Morphologic features and the genesis of incomplete septal cirrhosis. Arch Pathol Lab Med 2000; 124: 1599-1607.

8. Hammel P, Couvelard A, O'Toole D, Ratouis A, Sauvanet A, Flejou JF, et al. Regression of liver fibrosis after biliary drainage in patients with chronic pancreatitis and stenosis of the common bile duct. N Engl J Med 2001; 344: 418-423.

9. Desmet VJ, Roskams T. Cirrhosis reversal: a duel between dogma and myth. J Hepatol 2004; 40: 860-867.

10. Iredale JP. Models of liver fibrosis: exploring the dynamic nature of inflammation and repair in a solid organ. J Clin Invest 2007; 117: 539-548.

11. Cameron GR, Karunaratne WAE. Carbon tetrachloride cirrhosis in relation to liver regeneration. $J$ Pathol Bacteriol 1936; 42: 1-21.

12. McLean EK, McLean AE, Sutton PM. Instant cirrhosis. An improved method for producing cirrhosis of the liver in rats by simultaneous administration of carbon tetrachloride and phenobarbitone. Br J Exp Pathol 1969; 50: 502-506.

13. Hall PD, Plummer JL, Ilsley AH, Cousins MJ. Hepatic fibrosis and cirrhosis after chronic administration of alcohol and "low-dose" carbon tetrachloride vapor in the rat. Hepatology 1991; 13: 815-819.

14. Iredale JP, Benyon RC, Pickering J, McCullen M, Northrop $\mathrm{M}$, Pawley S, et al. Mechanisms of spontaneous resolution of rat liver fibrosis. Hepatic stellate cell apoptosis and reduced hepatic expression of metalloproteinase inhibitors. $J$ Clin Invest 1998; 102: 538-549.

15. Brandao CG, Ferreira HH, Piovesana H, Polimeno NC, Ferraz JG, de Nucci G, et al. Development of an experimental model of liver cirrhosis in rabbits. Clin Exp Pharmacol Physiol 2000; 27: 987-990.

16. Perez Tamayo R. Is cirrhosis of the liver experimentally produced by $\mathrm{CCl} 4$ and adequate model of human cirrhosis? Hepatology 1983; 3: 112-120.

17. Lieber CS. Ethanol metabolism, cirrhosis and alcoholism. Clin Chim Acta 1997; 257: 59-84.

18. Kato J, Sato Y, Inui N, Nakano Y, Takimoto R, Takada K, et al. Ethanol induces transforming growth factor-alpha expression in hepatocytes, leading to stimulation of collagen synthesis by hepatic stellate cells. Alcohol Clin Exp Res 2003; 27: 58S-63S.

19. Lieber CS. Alcohol and fibrogenesis. Alcohol Alcohol Suppl 1991; 1: 339-344.

20. Wu J, Liu SL, Zhu JL, Norton PA, Nojiri S, Hoek JB, et al. Roles of tissue transglutaminase in ethanol-induced inhibition of hepatocyte proliferation and alpha 1-adrenergic signal transduction. J Biol Chem 2000; 275: 22213-22219.

21. Sampey BP, Stewart BJ, Petersen DR. Ethanol-induced modulation of hepatocellular extracellular signal-regulated kinase-1/2 activity via 4-hydroxynonenal. J Biol Chem 2007; 282: 1925-1937.

22. Colantoni A, Idilman R, De Maria N, La Paglia N, Belmonte $\mathrm{J}$, Wezeman F, et al. Hepatic apoptosis and proliferation in male and female rats fed alcohol: role of cytokines. Alcohol Clin Exp Res 2003; 27: 1184-1189.

23. Li J, Hu W, Baldassare JJ, Bora PS, Chen S, Poulos JE, et al. The ethanol metabolite, linolenic acid ethyl ester, stimulates mitogen-activated protein kinase and cyclin signaling in hepatic stellate cells. Life Sci 2003; 73: 1083-1096.

24. Piacentini M, Farrace MG, Hassan C, Serafini B, Autuori F. 'Tissue' transglutaminase release from apoptotic cells into extracellular matrix during human liver fibrogenesis. $J$ Pathol 1999; 189: 92-98.

25. Issa R, Zhou X, Trim N, Millward-Sadler H, Krane S, Benyon $\mathrm{C}$, et al. Mutation in collagen-1 that confers resistance to the action of collagenase results in failure of recovery from CCl4-induced liver fibrosis, persistence of activated hepatic stellate cells, and diminished hepatocyte regeneration. FASEB J 2003; 17: 47-49.

26. Lorand L, Graham RM. Transglutaminases: crosslinking enzymes with pleiotropic functions. Nat Rev Mol Cell Biol 2003; 4: 140-156.

27. Reeves PG, Nielsen FH, Fahey GC Jr. AIN-93 purified diets for laboratory rodents: final report of the American Institute of Nutrition ad hoc Writing Committee on the Reformulation of the AIN-76A Rodent Diet. J Nutr 1993; 123: 1939-1951.

28. Dolber PC, Spach MS. Conventional and confocal fluorescence microscopy of collagen fibers in the heart. $J$ Histochem Cytochem 1993; 41: 465-469.

29. Stegemann H, Stalder K. Determination of hydroxyproline. Clin Chim Acta 1967; 18: 267-273.

30. Sherlock S, Dooley J. The portal venous system and portal hypertension. In: Sherlock S, Dooley J (Editors), Diseases of the liver and biliary system. 11th edn. Williston: WileyBlackwell Publishing Ltd.; 2008.

31. Zhou X, Hovell CJ, Pawley S, Hutchings MI, Arthur MJ, Iredale JP, et al. Expression of matrix metalloproteinase-2 and -14 persists during early resolution of experimental liver fibrosis and might contribute to fibrolysis. Liver Int 2004; 24 : 492-501.

32. Johnson TS, Skill NJ, El Nahas AM, Oldroyd SD, Thomas $\mathrm{GL}$, Douthwaite JA, et al. Transglutaminase transcription and antigen translocation in experimental renal scarring. $J$ Am Soc Nephrol 1999; 10: 2146-2157.

33. Desmet VJ. Comments on cirrhosis reversal. Dig Liver Dis 2005; 37: 909-916.

34. Sherlock S, Dooley J. Hepatic cirrhosis. In: Sherlock S, Dooley J (Editors), Diseases of the liver and biliary system. 11th edn. Williston: Wiley-Blackwell Publishing Ltd.; 2008. p 368-377.

35. Friedman SL. Stellate cell activation in alcoholic fibrosis - an overview. Alcohol Clin Exp Res 1999; 23: 904-910.

36. Nieto N, Friedman SL, Cederbaum Al. Stimulation and proliferation of primary rat hepatic stellate cells by cytochrome P450 2E1-derived reactive oxygen species. Hepatology 2002; 35: 62-73.

37. Svegliati-Baroni G, Inagaki $Y$, Rincon-Sanchez AR, Else C, Saccomanno S, Benedetti A, et al. Early response of alpha2(I) collagen to acetaldehyde in human hepatic stellate cells is TGF-beta independent. Hepatology 2005; 42: 343-352.

38. Verderio EA, Johnson T, Griffin M. Tissue transglutaminase in normal and abnormal wound healing: review article. Amino Acids 2004; 26: 387-404. 